\title{
PERAN RELIGIUSITAS DALAM MENINGKATKAN KINERJA KARYAWAN MUSLIM
}

\author{
Setiawan $^{1}$, Hasbi Assidiki Mauluddi ${ }^{2}$, dan Ine Mayasari ${ }^{3}$ \\ 1,2,3Program Studi Keuangan Syariah \\ Politeknik Negeri Bandung \\ Email : setiawan@polban.ac.id ${ }^{1}$, hasbi.assidiki@polban.ac.id², \\ inemayasari@polban.ac.id ${ }^{3}$
}

\begin{abstract}
ABSTRAK
Penelitian ini berusaha untuk mengeksplorasi kinerja karyawan yang dipengaruh oleh religiusitas. Berbeda dengan penelitian sebelumnya, penelitian ini menggunakan dimensi yang lebih spesifik pada religiusitas yang meliputi keyakinan dalam beragama, pengamalan dalam beragama, dan takut terhadap balasan atau siksaan. Data diperoleh dari 300 responden di Kota Bandung menggunakan kuesioner. Analisis data yang digunakan adalah SEM-PLS. Hasil penelitian menunjukkan bahwa dimensi pengamalan dalam beragama berpengaruh positif dan signifikan terhadap kinerja karyawan. sementara dimensi keyakinan dalam beragama dan takut terhadap balasan atau siksaan terhadap kinerja karyawan tidak berpengaruh signifikan. Hasil penelitian ini diharapkan dapat mendorong para manajer di perusahaan untuk melibatkan para karyawannya dalam kegiatan-kegiatan yang berkaitan dengan keagamaan ataupun sosial.
\end{abstract}

Kata Kunci: religiusitas, kinerja karyawan, karyawan muslim

\begin{abstract}
This study seeks to explore employee performance which is influenced by religiosity. In contrast to previous studies, this study uses a more specific dimension of religiosity which includes religios belief, religious involvement, and fear of divine punishment. Data obtained from 300 respondents in the city of Bandung using a questionnaire. The data analysis used was SEM-PLS. The results showed that the dimensions of practicing religion had a positive and significant effect on employee performance. Meanwhile, the dimensions of belief in religion and fear of reprisal or torture for employee performance do not have a significant effect. The results of this study are expected to encourage managers in the company to involve their employees in activities related to religion or social.
\end{abstract}

Keywords: religiosity, employee performance, muslim employees 


\section{PENDAHULUAN}

Sekarang ini semua entitas bisnis dihadapkan pada persaingan yang sangat ketat guna mengimbangi perkembangan dunia bisnis yang semakin cepat (Alfisyah \& Anwar, 2018). Hal ini menuntut perusahaan-perusahaan untuk lebih cermat dalam mempertimbangkan semua aspek yang dapat mendukung perusahaan dalam menghadapi persaingan. Tidak terkecuali aspek sumber daya manusia atau sering kita sebut sebagai SDM. SDM bagi perusahaan telah menjadi bagian terpenting karena tanpa dukungan SDM yang berkualitas maka aspek apapun tidak akan berjalan dengan baik. Sebaik apapun teknologi yang digunakan perusahaan, bila tidak didampingi oleh SDM yang berkualitas maka teknologi tersebut tidak akan bermanfaat secara optimal. Dengan mengingat peran yang sangat mendesak dari SDM ini maka perusahaan harus terus meningkatkan pengetahuan dan kemampuan SDM-nya agar menjadi amunisi perusahaan menghadapi persaingan bisnis global.

SDM berkualitas pada sebuah perusahaan biasanya ditunjukkan oleh kinerjanya di perusahaan. Menurut Robbins \& Timothy (2013), kinerja pegawai bisa ditunjukkan melalui capaian seseorang baik secara kuantitas ataupun kualitas dalam menjalankan tanggung jawab sesuai tugas yang diberikan. Karyawan dapat menunjukkan kinerja yang baik bila didorong oleh kekuatan dari dalam dirinya sendiri, seperti suasana psikologis. Suasana psikologis ini merupakan motivasi terbaik yang dapat menaikkan kinerja karyawan, sehingga dapat diduga bahwa karyawan yang tidak produktif dapat disebabkan oleh adanya masalah pada motivasi kerjanya (Alfisyah \& Anwar, 2018).

Namun demikian, pekerjaan selalu dikaitkan dengan kegiatan fisik ataupun pikiran semata, sehingga kegiatan ini acapkali menghabiskan waktu yang panjang. Hasil studi menunjukkan bahwa banyak pekerja terlalu banyak menghabiskan waktu mereka di tempat kerja serta kegiatan sosial yang ada kaitannya dengan pekerjaan dan beberapa memiliki lebih sedikit waktu untuk hal lain (de Klerk, 2005; Osman-Gani dkk., 2013). Hal ini harus menjadi perhatian, karena memungkinkan timbulnya konflik dari dalam diri perkerja yang pada gilirannya dapat bertransformasi menjadi stres (Tarwaka \& Sudiajeng, 2004). Di lain pihak kini 
banyak pekerja yang memiliki keinginan untuk memenuhi kebutuhan spiritual mereka (Osman-Gani dkk., 2013). Namun karena kesibukannya tersebut, mereka tidak dapat melakukannya karena keterbatasan waktu.

Mayoritas karyawan ingin menemukan makna dalam pekerjaannya (Sharabi, 2009), sehingga tidak sedikit organisasi mulai serius pada penciptaan suasana kerja yang sarat dengan makna ataupun tujuan jangka panjang. Banyak perusahaan yang mendorong perkembangan tren baru ini karena mereka percaya lingkungan kerja yang humanistik menciptakan situasi win-win untuk karyawan dan organisasi (Garcia-Zamor, 2003). Situasi yang diharapkan dalam hal ini adalah keterikatan para pekerja terhadap suasana agamis yang mereka anut. Literatur terdahulu telah menunjukkan bahwa faktor religiusitas yang dimiliki oleh para pekerja dapat berdampak positif pada kinerja mereka (Alfisyah \& Anwar, 2018; Osman-Gani dkk., 2013)

Istilah religiusitas sering disandingkan dengan istilah agama, dan keduanya digunakan secara bergantian untuk mendefinisikan konsep yang sama; itu adalah penghormatan, pengabdian, dan keyakinan individu terhadap ketuhanan (Souiden \& Marzouki, 2015). Religiusitas memperlihatkan tingkatan kepatuhan individu pada praktik ataupun keyakinan keagamaan pada kehidupan sehari-hari (Mansour \& Diab, 2016). Definisi ini menyiratkan bahwa religiusitas merupakan indikasi turunan seseorang terhadap agamanya. Komitmen pribadi untuk mematuhi aturan ilahi tidak hanya memengaruhi komunikasi sosial pribadinya tetapi juga dalam menjalankan segala kewajibannya.

Basis literatur yang berkembang memperlihatkan adanya hubungan yang kuat antara religiusitas seseorang dengan kehidupan keseharian yang bersangkutan (Osman-Gani dkk., 2013). Termasuk di dalamnya memperlihatkan bagaimana orang bekerja, berperilaku, ataupun hidup pada umumnya. Religiusitas dapat memberikan warna berbeda bagi seseorang untuk berperilaku termasuk bagi karyawan ketika bekerja. Karena keyakinan beragama dapat memberikan panduan bagi karyawan dalam mengambil keputusan, terlebih pada lingkungan yang multireligius dan multikultural. Meskipun demikian, terdapat kesenjangan 
penelitian yang signifikan yang menghubungkan religiusitas dengan kinerja karyawan dalam organisasi. Literatur terdahulu hanya memandang hubungan religiusitas dalam konteks utuh variabel (lihat: Moon dkk., 2020; Osman-Gani dkk., 2013). Penelitian ini ingin melihat pengaruh religiusitas dalam dimensi lain, seperti yang diungkap Souiden \& Marzouki (2015), bahwa religiusitas terdiri dari keyakinan dalam beragama, pengamalan dalam beragama, dan takut terhadap balasan atau siksaan. Dengan demikian, tujuan penelitian ini adalah untuk mengeksplorasi kinerja karyawan muslim yang digerakkan oleh religiusitas.

\section{METODE PENELITIAN}

Penelitian ini bersifat kausalitas dengan melihat hubungan variabel religiusitas dan kinerja karyawan. Data diperoleh secara langsung dari 300 karyawan Muslim di Kota Bandung dari berbagai latar belakang perkerjaan dengan menggunakan kuesioner. Setiap item jawaban pertanyaan diukur melalui Skala Likert (1-5). Variabel pada penelitian ini yaitu religiusitas yang diwakili oleh keyakinan dalam beragama, pengamalan dalam beragama, dan takut terhadap balasan atau siksaan dan kinerja karyawan. Berikut model dalam penelitian ini:

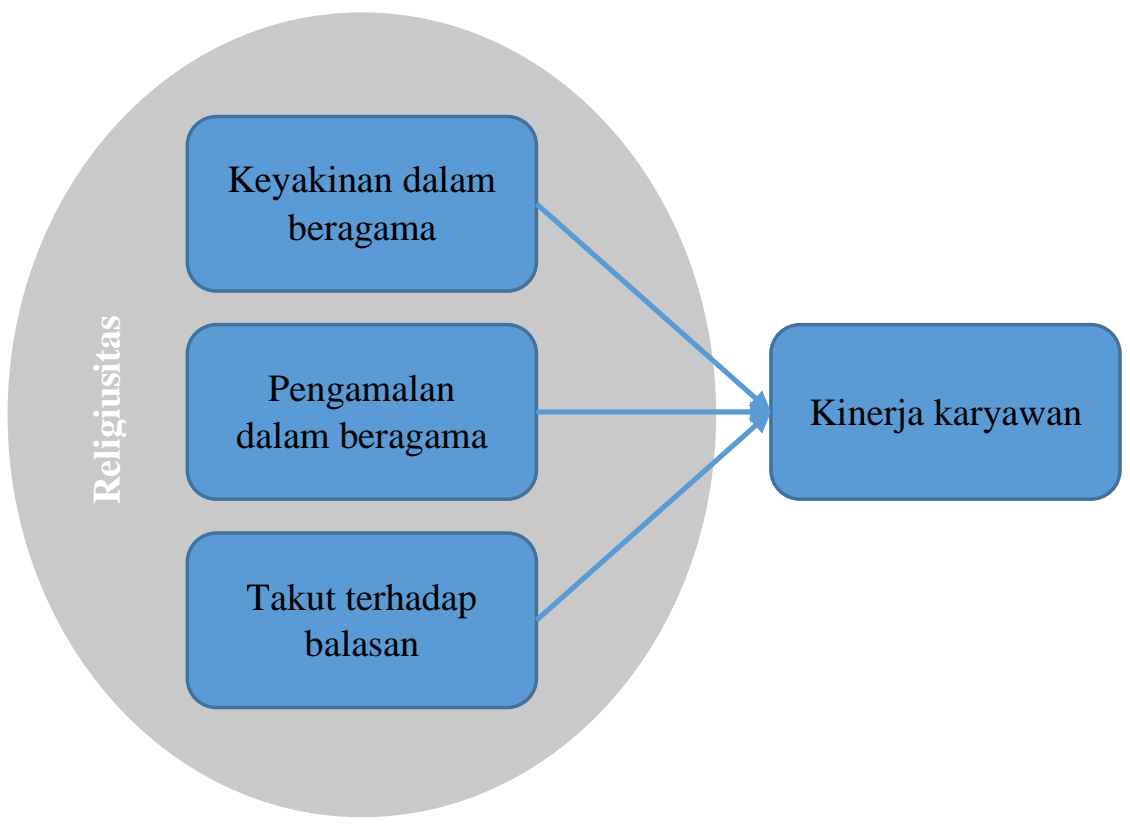

Gambar 1. Hubungan Religiusitas dan Kinerja Karyawan 
Analisis penelitian ini menggunakan model persamaan struktural berbasis varians (PLS) untuk menguji model yang dihipotesiskan karena beberapa alasan. Pertama, menilai data multivariat menunjukkan bahwa data tidak berdistribusi normal. Dengan demikian, asumsi penerapan model persamaan struktural (SEM) untuk menguji model yang diusulkan tidak memuaskan. Kedua, SEM berbasis varian (PLS) cocok untuk studi yang dimaksudkan untuk mengeksplorasi hubungan antara konstruk dan untuk mengukur validitas prediksi variabel eksogen (Hair, Jr. dkk., 2016). Dengan demikian, karena tujuan penelitian ini untuk menguatkan teori dan data yang tidak memiliki distribusi normal, maka pengujian model yang diusulkan dengan menggunakan variance-based SEM (PLS) dianggap tepat. Adapun analisis akan dibantu aplikasi WarpPLS versi 7.

\section{HASIL DAN PEMBAHASAN}

Setelah data berhasil dikumpulkan maka terlebih dahulu disajikan deskripsi dari responden yang disajikan pada tabel 1 .

Tabel 1. Deskripsi Responden

\begin{tabular}{|c|l|c|c|}
\hline Komponen & \multicolumn{1}{|c|}{ Deskripsi } & Frekuensi & Persentase \\
\hline \multirow{3}{*}{ Gender } & Laki-laki & 187 & $62,33 \%$ \\
\cline { 2 - 4 } & Perempuan & 113 & $37,67 \%$ \\
\hline \multirow{4}{*}{ Umur } & $<25$ tahun & 125 & $41,67 \%$ \\
\cline { 2 - 4 } & $25-34$ tahun & 112 & $37,33 \%$ \\
\cline { 2 - 4 } & $35-44$ tahun & 35 & $11,67 \%$ \\
\cline { 2 - 4 } & $>45$ tahun & 28 & $9,33 \%$ \\
\hline \multirow{4}{*}{ Pendidikan } & $<$ SMA/sederajat & 26 & $8,67 \%$ \\
\cline { 2 - 4 } & SMA/sederajat & 116 & $38,67 \%$ \\
\cline { 2 - 4 } & Diploma/sarjana & 137 & $45,67 \%$ \\
\cline { 2 - 4 } & Pascasarjana & 21 & $7,00 \%$ \\
\hline
\end{tabular}

Pada tabel 1 mengenai deskripsi responden dapat dilihat bahwa responden laki-laki mendominasi dengan jumlah 187 orang atau 62,33\%, sementara perempuan 113 orang atau 37,67\%. Berdasarkan umurnya, responden dengan umur di bawah 25 tahun sebanyak 125 orang atau 41,67\%, rentang umur 25 sampai 44 tahun sebanyak 112 orang atau 37,33\%, rentang umur 35 sampai 44 tahun sebanyak 35 orang atau $11,67 \%$, dan sisanya berumur di atas 45 tahun sebanyak 28 orang 
atau $9,33 \%$. Berdasarkan pendidikannya, responden dengan pendidikan di bawah SMA sebanyak 26 orang atau 8,67\%, berpendidikan SMA/sederajat sebanyak 116 orang atau $38,67 \%$, berpendidikan diploma atau sarjana sebanyak 137 orang atau $45,67 \%$, dan yang berpendidikan pascasarjana sebanyak 21 orang atau $7 \%$.

Setelah diidentifikasi responden dalam penelitian ini, maka selanjutnya adalah melakukan analisis data dengan menguji validitas dan reliabilitas instrumen. Berikut disajikan pada tabel 2 hasil pengujian validitas dan reliabilitas.

Tabel 2. Uji Validitas dan Reliabilitas

\begin{tabular}{|c|c|c|c|c|}
\hline Konstruk/Item & Loading & Cron-bach $\boldsymbol{\alpha}$ & $\boldsymbol{C R}$ & $\boldsymbol{A V E}$ \\
\hline Keyakinan dalam beragama & & 0,931 & 0,948 & 0,887 \\
\hline Key1 & 0,879 & & & \\
Key2 & 0,896 & & & \\
Key3 & 0,942 & & & \\
Key4 & 0,927 & & & \\
Key5 & 0,782 & & 0,911 & 0,712 \\
\hline Pengamalan dalam beragama & & 0,891 & & \\
\hline Pen1 & 0,704 & & & \\
Pen2 & 0,742 & & & \\
Pen3 & 0,742 & & & \\
Pen4 & 0,627 & & & \\
Pen5 & 0,755 & & & \\
Pen6 & 0,757 & & & \\
Pen7 & 0,690 & & & \\
Pen8 & 0,729 & & & \\
Pen9 & 0,667 & & & \\
Pen10 & 0,692 & & & \\
\hline Takut terhadap balasan atau siksaan & & 0,854 & 0,897 & 0,798 \\
\hline Tak1 & 0,841 & & & \\
Tak2 & 0,869 & & & \\
Tak3 & 0,880 & & & \\
Tak4 & 0,683 & & & \\
Tak5 & 0,696 & & & \\
\hline Kinerja karyawan & & 0,836 & 0,875 & 0,685 \\
\hline Kkar1 & 0,603 & & & \\
Kkar2 & 0,723 & & & \\
Kkar3 & 0,718 & & & \\
Kkar4 & 0,791 & & & \\
Kkar5 & 0,698 & & & \\
Kkar6 & 0,620 & & & \\
Kkar7 & 0,600 & & & \\
Kkar8 & 0,702 & & & \\
\hline & & & & \\
\hline
\end{tabular}


Pada hasil pengujian pada tabel 2, diketahui bahwa seluruh item indikator dari setiap variabel bernilai di atas 0,5, yang artinya terpenuhi kriteria validitas konvergen. Begitupun pada tinjauan validitas konvergen melalui nilai AVE yang menunjukkan seluruh variabel di atas 0,50. Untuk nilai Cronbach's alpha sebagai penilaian composite reliability menunjukkan nilai di atas 0,70 , begitupun dengan nilai cronbach's alpha yang di atas 0,50. Dengan demikian seluruh variabel dikatakan valid dan realibel.

Tabel 3. Analisis Fit Model

\begin{tabular}{|l|l|c|c|}
\hline \multicolumn{1}{|c|}{ Keterangan } & \multicolumn{1}{|c|}{ Cut Value } & Hasil & Evaluasi \\
\hline Average path coefficient & $\mathrm{P}=0.002$ & 0,183 & Model Fit \\
\hline Average $R$-squared & $\mathrm{P}<0.001$ & 0,259 & Model Fit \\
\hline Average adjusted $R$-squared & $\mathrm{P}<0.001$ & 0,251 & Model Fit \\
\hline Average block VIF & $\begin{array}{l}\text { acceptable if }<=5, \\
\text { ideally }<=3.3\end{array}$ & 2,324 & Ideal \\
\hline Average full collinearity VIF & $\begin{array}{l}\text { acceptable if }<=5, \\
\text { ideally }<=3.3\end{array}$ & 2,312 & Ideal \\
\hline Tenenhaus GoF & $\begin{array}{l}\text { small }>=0.1, \text { medium } \\
>=0.25, \text { large }>=0.36\end{array}$ & 0,394 & Besar \\
\hline Sympson's paradox ratio & $\begin{array}{l}\text { acceptable if }>=0.7, \\
\text { ideally }=1\end{array}$ & 1.000 & Ideal \\
\hline R-squared contribution ratio & $\begin{array}{l}\text { acceptable if }>=0.9, \\
\text { ideally }=1\end{array}$ & 1.000 & Ideal \\
\hline Statistical suppression ratio & acceptable if $>=0.7$ & 1.000 & Diterima \\
\hline $\begin{array}{l}\text { Nonlinear bivariate causality } \\
\text { direction ratio }\end{array}$ & acceptable if $>=0.7$ & 1.000 & Diterima \\
\hline
\end{tabular}

Selanjutnya pada tabel 3 merupakan hasil dari pengujian kecocokan model yang terdiri dari 10 kriteria. Berdasarkan ambang batas dapat dikatakan semua kriteria model terpenuhi dengan baik.

Tabel 4. Model Struktural

\begin{tabular}{|l|c|c|c|}
\hline \multicolumn{1}{|c|}{ Jalur Hubungan } & Koefisien & $P$-value & Keterangan \\
\hline $\begin{array}{l}\text { Keyakinan dalam beragama => Kinerja } \\
\text { karyawan }\end{array}$ & 0,057 & 0.159 & $\begin{array}{c}\text { Tidak } \\
\text { signifikan }\end{array}$ \\
\hline $\begin{array}{l}\text { Pengamalan dalam beragama => Kinerja } \\
\text { karyawan }\end{array}$ & 0,449 & $<0.001$ & Signifikan \\
\hline $\begin{array}{l}\text { Takut terhadap balasan atau siksaan => } \\
\text { Kinerja karyawan }\end{array}$ & 0,042 & 0,234 & $\begin{array}{c}\text { Tidak } \\
\text { signifikan }\end{array}$ \\
\hline
\end{tabular}


Terakhir merupakan model struktural yang disajikan pada tabel 4. Hasilnya menunjukkan bahwa 'keterlibatan dalam beragama' memiliki pengaruh signifikan terhadap kinerja karyawan. Dimensi lainnya dalam religiusitas tidak berpengaruh signifikan. Sementara secara keseluruhan, model menunjukkan bahwa religiusitas berpengaruh positif dan signifikan terhadap kinerja karyawan. hal ini ditujukkan pada tabel 3, yaitu nilai average adjusted $R$-squared sebesar 25,1 persen.

Pengamalan dalam beragama merupakan keterlibatan langsung si karyawan pada tindakan-tindakan nyata yang menggambarkan nilai-nilai keagamaan. Dalam hal ini contohnya adalah aktif dalam pengajian, aktif mengikuti kegiatan keorganisasian, turun tangan dalam membantu sesama yang terkena bencana, dan banyak hal lainnya. Karyawan yang memiliki tingkat religiusitas yang baik dengan pengamalan-pengamalan nyata pada nilai agama lebih cenderung memiliki dorongan yang kuat untuk bekerja dengan baik, sehingga umumnya mereka akan memiliki kinerja yang baik pula di tempat kerja. Praktik keagamaan yang dilakukan pada keseharian Muslim akan menjadi kebiasaan yang terus dilakukan pada kegiatan lainnya. Pekerjaan di tempat kerja pun dijalani seolah mereka sedang mempraktikan amalan ibadah.

Temuan penelitian ini melengkapi temuan-temuan sebelumnya yang melihat religiusitas secara utuh. Namun ternyata, nilai religiusitas yang dapat menjadi motivasi para karyawan melakukan pekerjaan sebaik mungkin adalah pengamalan dalam beragama. Namun secara keseluruhan, religiusitas berpengaruh positif dan signifikan terhadap kinerja karyawan seperti yang terlihat pada tabel 4. Penelitian ini sejalan dengan temuan (Osman-Gani dkk., 2013).

\section{KESIMPULAN DAN SARAN}

Berdasarkan hasil penelitian menunjukkan bahwa dimensi pengamalan dalam beragama menjadi satu-satunya dimensi dari religiusitas yang berpengaruh terhadap kinerja karyawan. Dua dimensi lain yaitu keyakinan dalam beragama dan takut terhadap balasan tidak berpengaruh signifikan terhadap kinerja karyawan. Bagi para manajer di perusahaan diharapkan dapat membuat kebijakan yang mendorong para 
karyawannya (terutama yang muslim) untuk melakukan kegiatan-kegiatan fisik yang berkaitan dengan keagamaan dan sosial, seperti kegiatan bantuan sosial perusahaan, kegiatan pengajian, dana kegiatan lainnya. Hal ini untuk mengarahkan para karyawan tergerak dan terbiasa untuk melakukan pengamalan beragama, sehingga diharapkan ke depannya hal tersebut menjadi motivasi untuk menaikkan prestasinya dalam bekerja.

Bagi peneliti selanjutnya, dapat dieksplorasi variabel religiusitas pada penelitian ini dengan cakupan yang lebih luas, seperti objek yang lebih banyak ataupun dengan menyesuaikan pada penganut agama lainnya. Dapat pula diteliti variabel mediasi antara religiusitas dan kinerja karyawan untuk melihat kemungkinan pengaruh tidak langsung yang dapat memperkuat pengaruh dua variabel tersebut.

\section{DAFTAR PUSTAKA}

Alfisyah, K. D., \& Anwar, Moch. K. (2018). Pengaruh Religiusitas terhadap Kinerja Karyawan Muslim Kantor. Jurnal Ekonomi Islam, 1(2), 99-107.

de Klerk, J. J. (2005). Spirituality, Meaning in Life, and Work Wellness: A Research Agenda. International Journal of Organizational Analysis, 13(1), 64-68. https://doi.org/10.1108/eb028998

Garcia-Zamor, J.-C. (2003). Workplace Spirituality and Organizational Performance. Public Administration Review, 63(3), 355-363. https://doi.org/10.1111/1540-6210.00295

Hair, Jr., J. F., M. Hult, G. T., Ringle, C., \& Sarstedt, M. (2016). A Primer on Partial Least Squares Structural Equation Modeling (PLS-SEM). Sage Publications.

Mansour, I. H. F., \& Diab, D. M. E. (2016). The relationship between celebrities' credibility and advertising effectiveness: The mediation role of religiosity. Journal of Islamic Marketing, 7(2), 148-166. https://doi.org/10.1108/JIMA-05-2013-0036

Moon, T.-W., Youn, N., Hur, W.-M., \& Kim, K.-M. (2020). Does employees' spirituality enhance job performance? The mediating roles of intrinsic motivation and job crafting. Current Psychology, 39(5), 1618-1634. https://doi.org/10.1007/s12144-018-9864-0 
Osman-Gani, Aa. M., Hashim, J., \& Ismail, Y. (2013). Establishing linkages between religiosity and spirituality on employee performance. Employee Relations, 35(4), 360-376. https://doi.org/10.1108/ER-04-2012-0030

Robbins, S. P., \& Timothy, A. (2013). Organizational behavior (15th ed.). Prentice Hall.

Sharabi, M. (2009). Work values, employment and ethnicity: Jewish and Muslim academic graduates in Israel. Cross Cultural Management: An International Journal, 16(4), 398-409. https://doi.org/10.1108/13527600911000366

Souiden, N., \& Marzouki, R. (2015). Consumer attitudes and purchase intentions toward Islamic banks: The influence of religiosity. International Journal of Bank Marketing, 33(2), 143-161. https://doi.org/10.1108/IJBM-10-20130115

Tarwaka, B. S. H., \& Sudiajeng, L. (2004). Ergonomi untuk Keselamatan, Kesehatan Kerja dan Produktivitas. UNIBA Press. 